\title{
Structural Diversity in Early-Stage Biofilm Formation on Microplastics Depends on Environmental Medium and Polymer Properties
}

\author{
Anja F. R. M. Ramsperger ${ }^{1,4}$, Anja C. Stellwag ${ }^{1}$, Anja Caspari ${ }^{2}$, Andreas Fery ${ }^{2}{ }^{\circledR}$, \\ Tillmann Lueders ${ }^{3}$, Holger Kress ${ }^{4}$, Martin G. J. Löder ${ }^{1}(\mathbb{D})$ and Christian Laforsch ${ }^{1}$ * \\ 1 Animal Ecology I, University of Bayreuth, 95447 Bayreuth, Germany; \\ anja.ramsperger@uni-bayreuth.de (A.F.R.M.R.); anja.stellwag@uni-bayreuth.de (A.C.S.); \\ martin.loeder@uni-bayreuth.de (M.G.J.L.) \\ 2 Institut für Physikalische Chemie und Physik der Polymere, Leibniz Institut für Polymerfoschung \\ Dresden e.V., 01069 Dresden, Germany; caspari@ipfdd.de (A.C.); fery@ipfdd.de (A.F.) \\ 3 Ecological Microbiology, University of Bayreuth, 95447 Bayreuth, Germany; \\ tillmann.lueders@uni-bayreuth.de \\ 4 Biological Physics, University of Bayreuth, 95447 Bayreuth, Germany; holger.kress@uni-bayreuth.de \\ * Correspondence: Christian.laforsch@uni-bayreuth.de; Tel.: +49-921-552650
}

Received: 30 September 2020; Accepted: 13 November 2020; Published: 17 November 2020

\begin{abstract}
Plastics entering the environment can not only undergo physical degradation and fragmentation processes, but they also tend to be colonized by microorganisms. Microbial colonization and the subsequent biofilm formation on plastics can alter their palatability to organisms and result in a higher ingestion as compared to pristine plastics. To date, the early stage of biofilm formation on plastic materials has not been investigated in context of the environmental medium and polymer properties. We explored the early-stage biofilm formation on polyamide (PA), polyethylene terephthalate (PET), and polyvinyl chloride (PVC) after incubation in freshwater and artificial seawater and categorized the structural diversity on images obtained via scanning electron microscopy. Furthermore, by the measurement of the initial $\zeta$-potential of the plastic materials, we found that PA with the highest negative $\zeta$-potential tended to have the highest structural diversity, followed by PET and PVC after incubation in freshwater. However, PVC with the lowest negative $\zeta$-potential showed the highest structural diversity after incubation in seawater, indicating that the structural diversity is additionally dependent on the incubation medium. Our results give insights into how the incubation medium and polymer properties can influence the early-stage biofilm formation of just recently environmentally exposed microplastics. These differences are responsible for whether organisms may ingest microplastic particles with their food or not.
\end{abstract}

Keywords: microplastic; plastic; biofilm; SEM; $\zeta$-potential; EPS

\section{Introduction}

Plastic materials have a considerable number of favorable properties, amongst others their lightweight, versatility, and longevity [1]. However, once plastics enter the environment, their longevity is a disadvantage that prevents their degradation and promotes their accumulation in the environment [2]. There, most plastic items break down into smaller pieces. Those smaller plastic particles are defined as microplastic particles [3] if their size is smaller than $5 \mathrm{~mm}$ [4]. Meanwhile, microplastic particles are detected in all environmental compartments, ranging from marine [5] and limnetic environments [6] over soils [7] up to the atmosphere [8,9]. The occurrence of microplastic particles in the environment is not necessarily restricted to areas of high human activities such as 
in urban areas because microplastic particles are also found in remote mountain lakes [10], remote islands [11], the Antarctica [12], and even in the deep sea [13]. Once plastics enter an environmental compartment, they may pose a risk to the associated organisms, for example due to the ingestion of plastic items [14]. Already thirty years ago, Harper and Fowler [15] described the ingestion of plastic items by sea birds. By now, the ingestion of microplastic particles has been shown in a variety of organisms within the food web, starting at the bottom with zooplankton $[10,16]$ and mussels [17,18] going up to vertebrates such as fish $[14,19,20]$ and right up to humans $[9,21,22]$. Although there is no broad evidence for plastic ingestion-related mortality [14], internal blockage or lesions of the digestive tract and a false feeling of satiation due to indigestible plastic filling up the stomach was described to negatively affect associated organisms and may lead to their death [20,23]. In addition to those physical risks, microplastics are controversially discussed to act as vectors for adsorbed hazardous chemicals [24] or pathogenic microorganisms [25]. The ingestion of microplastic particles has been found to be enhanced for weathered particles [26,27], i.e., particles exposed longer to environmental influences, thereby undergoing degradation and fragmentation processes [2,28]. Next to those physicochemical changes, plastics released to the environment are typically also rapidly colonized by microbes. The observed enhanced ingestion by organisms after the aging of microplastics was suggested to be due to the presence of a biofilm masking the plastics by mimicking an organic origin and thus altering the palatability of the particles [27]. Unfortunately, the exposure time for microplastics collected from the environment cannot be determined but can theoretically be decades or longer. Biofilms on plastic materials have already been described in exposure experiments in the environment $[29,30]$ and on plastic materials collected directly from nature [30,31]. Such exposure experiments ranged from short time scales of days [32] and weeks [29,30] up to longer time scales of months [33,34] and years [35].

An initial coating with microbes is considered to occur within minutes to hours after the exposure in marine waters [36]. Renner and Weibel [37] described the five typical successive steps of biofilm formation as follows: First, microorganisms reversibly attach to surfaces via pili, flagella, or membrane proteins. By extruding extracellular polymeric substances (EPS), the second step of biofilm formation is initiated. At this point, microorganisms have already irreversibly attached to the surfaces, which can be defined as the early stage of a biofilm formation. In the third step, microorganisms embedded in the EPS proliferate, form smaller colonies, and release additional EPS. The microbial communities further proliferate and form three-dimensional structures described as the maturing of a substantial biofilm within the fourth step. Lastly, in the fifth step, cells can again detach from the biofilm and colonize newly available surfaces [37]. This description highlights that a mature biofilm is a highly complex and dynamic system controlled in addition to abiotic factors by many different biotic factors, including microbial interactions and competition [38]. Rummel et al. [39] emphasize in their comprehensive review that the surface properties of polymers, such as their roughness, surface energy, and charge or hydrophobicity may be relevant for biofilm formation. In this context, Hossain et al. [34] showed that the formation of a biofilm on microplastics in freshwater mesocosms that have been enriched with bacterial strains was dependent on the polymer type.

It has further been shown that an incubation period of two months already alters the initial polymers' physicochemical properties by microbial attachment [34]. However, to date, it has not been investigated whether the initial surface properties of different polymer types predefine the colonization in the early stage of a biofilm formation, or if colonization patterns of the same polymer differ between different environmental media. To fill this gap and to correlate the initial surface properties with the biofilm formation, we monitored the very early stage of biofilm formation $(0 \mathrm{~h}$ up to 14 days) in freshwater and artificial seawater on the surfaces of polyamide (PA), polyethylene terephthalate (PET), and polyvinyl chloride (PVC) fragments, which are three polymers that are produced in high amounts [40]. The chosen polymers highly differ in their chemical composition (PA-containing amid groups, PET-containing ester groups and PVC-containing chloride) resulting in different physicochemical properties, which allows a correlation of the early-stage biofilm formation 
with the polymers' properties. We visualized microorganisms and associated structures on the microplastic fragments' surfaces by using scanning electron microscopy (SEM). We compared the structural diversity of the biofilms by determining microbial and non-microbial structures on the polymer fragments for different incubation times and incubation media. To evaluate how the fragments' surface properties may influence the early stage biofilm formation, we measured the $\mathrm{pH}$-dependent initial $\zeta$-potential of the three polymer types. Additionally, the structural diversity on mature biofilms from a very late stage of biofilm formation (more than two years) on the surface of PA incubated in either freshwater or seawater was compared to the very early stage biofilm formation in our experiments. We hypothesize that due to the different initial properties of the chosen polymers, the very early stage of biofilm formation differs between polymers and incubation media and changes over time.

\section{Materials and Methods}

\subsection{Microplastic Particles}

Polymers were purchased as raw pellets from different suppliers (PA Pellets: Leibniz-Institut für Polymerforschung Dresden e.V.; Polymers used for fragments: PA: BASF, PET: Neogroup and PVC: Vinnolit; see Table 1). For long-term incubation of PA, the whole pellets were incubated without further processing. To obtain the microplastic fragments for the time-series incubation, the raw pellets were ground in an ultra-centrifugal mill (ZM 200 Retsch, Haan, Germany) with a 12-tooth rotor and a sieve size of $1000 \mu \mathrm{m}$ with 18,000 U/min. The milling was performed in liquid nitrogen to prevent the conglutination of the fragments. Subsequently, $10 \mathrm{~g}$ of the fragments were sieved using an Alpine air jet sieve (E200LS, Hosokawa Alpine, Augsburg, Germany) with mesh sizes of $125 \mu \mathrm{m}$ and $4000 \mathrm{~Pa}$ for $15 \mathrm{~min}$.

Table 1. Summary of the used polymers. The suppliers, the corresponding trading names, and size in $\mu \mathrm{m}$ after milling.

\begin{tabular}{cccc}
\hline Polymer Type & Supplier & Trade Name & Size Distribution [ $\boldsymbol{\mu m}$ ] \\
\hline Polyamide pellet $^{*}$ & $\begin{array}{c}\text { Leibniz-Institut für } \\
\text { Polymerforschung Dresden e.V. }\end{array}$ & $2000-2500$ \\
\hline Polyamid fragments & BASF, Ludwigshafen, Germany & Ultramid $^{\circledR}$, A3K, PA66 & $<500$ \\
\hline $\begin{array}{c}\text { Polyethylene } \\
\text { terephtalate fragments }\end{array}$ & $\begin{array}{c}\text { Neogroup, Klaipeda district, } \\
\text { Lithuania }\end{array}$ & Neopet 80 & $<500$ \\
\hline $\begin{array}{c}\text { Polyvinyl chloride } \\
\text { fragments }\end{array}$ & $\begin{array}{c}\text { Vinnolit GmbH \& Co.KG, } \\
\text { Ismaning, Germany }\end{array}$ & ${ }^{\circledR}$ Vinnolit S 3268 & $<500$ \\
\hline
\end{tabular}

* The polyamide pellet for the long-term experiment was not milled.

\subsection{Incubation of Microplastic Particles in Environmental Media}

PA pellets that were incubated in freshwater and seawater for approximately two years in a long-term experiment were used to investigate a mature late-stage biofilm on the surface of a microplastic particle for comparison with the biofilms of the short-term experiments. To monitor the early stage of biofilm formation, the polymer fragments were incubated in two environmental media, freshwater and seawater. Prior to incubation, the produced fragments of each polymer type were washed thoroughly in ultrapure water (Purelab Flex Elga, Veolia Water Technologies, Celle, Germany) to remove possible contamination from milling: $250 \mathrm{mg}$ of each polymer fragments were transferred to a $15 \mathrm{~mL}$ tube (CELLSTAR ${ }^{\circledR}$, Greiner Bio-One GmbH, Frickenhausen, Germany) and filled up with $10 \mathrm{~mL}$ ultrapure water. After carefully mixing for 30 seconds (Reax 2000, Heidolph Instruments $\mathrm{GmbH} \& \mathrm{Co}$. KG, Schwabach, Germany, pace 8), all polymers were homogeneously suspended. Subsequently, the samples were centrifuged ( $2500 \mathrm{~g}, 20 \mathrm{~min}$, room temperature), the supernatant was removed via pipetting, and the samples were resuspended in $10 \mathrm{~mL}$ of the respective environmental media. Before incubating each polymer type in the respective environmental media, samples were prepared for SEM images as a control. The freshwater for incubation was obtained 
from an artificial pond at the University of Bayreuth $\left(49^{\circ} 55^{\prime} 44.1^{\prime \prime} \mathrm{N} ; 11^{\circ} 34^{\prime} 60.0^{\prime \prime} \mathrm{E}\right)$, and seawater was obtained from a marine aquarium facility of the University of Bayreuth (sampling sites of the environmental media in Figure S1).

To analyze the time-dependent development of a biofilm, we sampled the fragments after 0 , $0.5,1,2,5,7,11$, and 14 days of incubation from the respective tube. For maintaining a vital microbial community during the incubation series, the respective media in the incubation tubes were exchanged three times per week after centrifugation, as described above. To avoid sedimentation of the microplastic fragments and obtain a homogeneous development of a biofilm on the particles' surface, the $15 \mathrm{~mL}$ tubes were placed in a hybridization furnace and continuously agitated to prevent sedimentation $\left(26.5 \pm 0.5^{\circ} \mathrm{C}, 9 \mathrm{rpm}\right)$.

\subsection{Sample Preparation for Scanning Electron Microscopy}

To visualize biofilm formation, the samples were analyzed using a scanning electron microscope (SEM, LEO1530 Zeiss, Oberkochen, Germany, magnification 500×-50,000×, 2-3 kV, SE2 detector). From each sample, $20 \mu \mathrm{L}$ were pipetted onto carbon conductive tabs (Ø $12 \mathrm{~mm}$ Plano GmbH, Wetzlar, Germany) fixed to aluminum stubs (Ø $12 \mathrm{~mm}$, Plano GmbH, Wetzlar, Germany). Then, the stubs were transferred into a desiccator, vacuum-dried, and stored until the images were acquired. Samples were subsequently sputter-coated with a two nm-thick platinum layer (208HR sputter coater, Cressington, Watford, UK) and visualized using the SEM. The structural diversity was further compared with SEM images from the literature [12,31,41-53]. Additionally, we investigated both incubation media, freshwater and seawater, as a blank for comparison with the samples. To do so, $20 \mu \mathrm{L}$ of the respective pure media without microplastics were pipetted onto the carbon conductive tabs and further processed as described.

\subsection{Classification of Observed Structural Diversity via SEM Images}

We compared the microorganismal and non-microorganismal structures in the SEM images and compared them with typical microbial structures found in the literature [12,31,41-53]. For instance, spherical structures resembling coccoid cellular structures were defined as coccoid bacteria (cc). A summary of all detected structures can be found in Table 2.

The overall number of different structures observed within the 14-day incubation were counted and defined as the biofilms' structural diversity. We categorized the structural diversity into low, medium, and high structural diversity (0-3, 4-6, and 7-9 numbers of different structures, respectively), depending on the number of the observed different structures.

Table 2. Summary of the biofilm structures. Abbreviations and associated structures from late and early stage biofilm formation were observed in SEM images.

\begin{tabular}{ccc}
\hline & \multicolumn{2}{c}{ Biofilm Structures } \\
\hline & Abbreviation & Associated Structure \\
\hline & compf & compartmented filaments \\
edia & flongated diatoms \\
& $\mathrm{f}$ & flagella-like \\
& $\mathrm{flag}$ & multicellular \\
& media & marine elongated diatoms \\
& $\mathrm{pEPS}$ & particulate EPS \\
& $\mathrm{res}$ & rough elliptical structure \\
& $\mathrm{sp}$ & sporous \\
& tmf & thin mucus-like film \\
& tub & tubular \\
\hline \multirow{2}{*}{} & &
\end{tabular}


Table 2. Cont.

\begin{tabular}{|c|c|c|}
\hline \multicolumn{3}{|r|}{ Biofilm Structures } \\
\hline & Abbreviation & Associated Structure \\
\hline \multirow{13}{*}{ 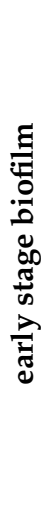 } & $\mathrm{a}$ & non-assignable/exceptional microorganismal structure \\
\hline & $\mathrm{CC}$ & coccoid bacteria \\
\hline & $\mathrm{cd}$ & centric diatom \\
\hline & $\mathrm{d}$ & diatom \\
\hline & $\mathrm{f}$ & filamentous structure \\
\hline & $\mathrm{mc}$ & multicellular \\
\hline & $\mathrm{p}$ & platelet \\
\hline & $\mathrm{rp}$ & round platelet \\
\hline & rod & rod-/vibrio-shaped bacteria \\
\hline & rodf & rod-/vibrio-shaped bacteria with flagella \\
\hline & sf & solid film \\
\hline & $\mathrm{tf}$ & thin film \\
\hline & uc & unicellular \\
\hline
\end{tabular}

\section{5. $\zeta$-Potential}

The $\zeta$-potential gives information about the electrostatic potential at the surfaces of the polymer of hydrodynamic shear or slipping plain surrounding a polymer particle and helps to predict how a particle may interact with other surfaces or soluble [54]. The $\zeta$-potential measurements were performed as recently described [55]. In brief, $200 \mathrm{mg}$ of each polymer type's fragments were investigated with the Electrokinetic Analyzer EKA (Anton Paar GmbH, Austria). The fragments were packed densely in a cylindrical powder cell with a diameter $12 \mathrm{~mm}$ and height $2 \mathrm{~mm}$ and covered at both ends with a $20 \mu \mathrm{m}$ pore sized membrane. After mounting the powder cells, $0.001 \mathrm{M} \mathrm{KCl}$ was streamed through the samples until an equilibrium was reached. The $\mathrm{pH}$ value was adjusted by adding $0.1 \mathrm{M} \mathrm{HCl}$ or $0.1 \mathrm{M} \mathrm{KOH}$ solution. The $\zeta$-potential was calculated as described in Drechsler et al. [55], without the correction for the surface conductivity, as the particle geometry was unknown for fragments.

\section{Results}

\subsection{Surface Properties— $\zeta$-Potential}

We measured the initial $\zeta$-potential via a $\mathrm{pH}$ titration, ranging from an acidic $\mathrm{pH}$ of 2 up to an alkaline $\mathrm{pH}$ of 9 . In the acidic $\mathrm{pH}$ range, PET showed the highest $\zeta$-potential, followed by PA and the lowest $\zeta$-potential for PVC. Within the $\mathrm{pH}$ titration, we observed the highest drop in $\zeta$-potential for PA (from $+12 \pm 0.1 \mathrm{mV}$ at $\mathrm{pH} 2.5$ to $-55 \pm 1 \mathrm{mV}$ at $\mathrm{pH}$ 8.9), followed by PET (from $+15 \pm 0.1 \mathrm{mV}$ at $\mathrm{pH} 2.6$ to $-39 \pm 1 \mathrm{mV}$ at $\mathrm{pH} 8.8$ ) and PVC showing the smallest drop in $\zeta$-potential (from $+3 \pm 1 \mathrm{mV}$ at $\mathrm{pH} 2.5$ to $-17 \pm 2 \mathrm{mV}$ at $\mathrm{pH} 8.9$ ) (Figure 1). Table 3 shows the $\zeta$-potential at $\mathrm{pH} 8$ which refers to the $\mathrm{pH}$ of both incubation media with PA showing the highest negative $\zeta$-potential, followed by PET and PVC showing the lowest negative $\zeta$-potential $(-55 \pm 1 \mathrm{mV},-43 \pm 1 \mathrm{mV}$ and $-15 \pm 1 \mathrm{mV}$, respectively).

Table 3. $\zeta$-potential at $\mathrm{pH} 8$, contact angles, and the overall number of structural diversities on the surfaces of the three polymers after the incubation in freshwater (FW) and seawater (SW) within two weeks.

\begin{tabular}{|c|c|c|c|c|}
\hline Polymer Type & $\zeta$-Potential (pH 8) & Contact Angle [56] & Environmental Media & $\begin{array}{l}\text { Biofilm Structural } \\
\text { Diversity [14 Days] }\end{array}$ \\
\hline \multirow{2}{*}{ PA } & \multirow[b]{2}{*}{$-55 \mathrm{mV}$} & \multirow{2}{*}{$70^{\circ}$} & FW & 9 \\
\hline & & & SW & 7 \\
\hline \multirow{2}{*}{ PET } & \multirow{2}{*}{$-43 \mathrm{mV}$} & \multirow{2}{*}{$81^{\circ}$} & FW & 6 \\
\hline & & & SW & 6 \\
\hline \multirow{2}{*}{ PVC } & \multirow{2}{*}{$-15 \mathrm{mV}$} & \multirow{2}{*}{$87^{\circ}$} & FW & 3 \\
\hline & & & SW & 8 \\
\hline
\end{tabular}




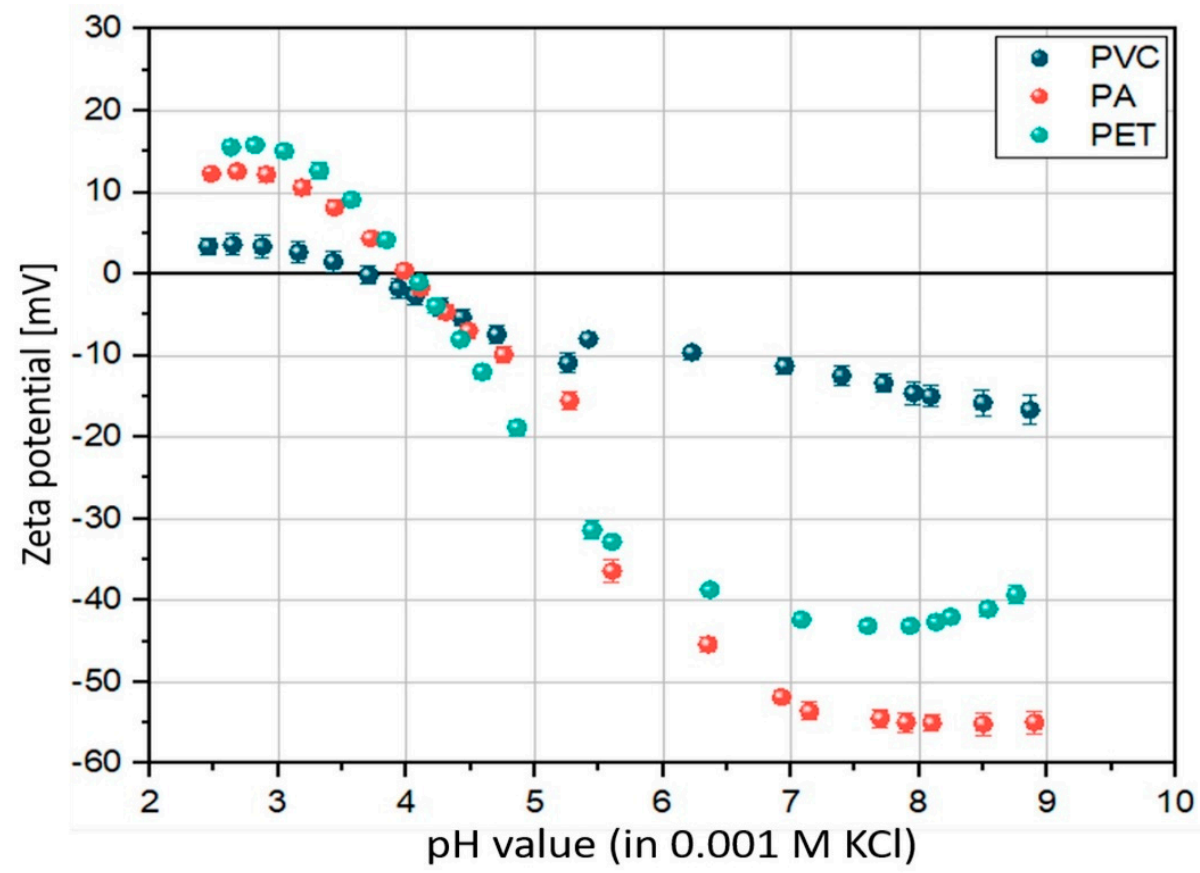

Figure 1. Zeta potential values of the three polymers versus $\mathrm{pH}$ value. The zeta potential was measured for polyvinyl chloride (PVC) (blue), polyamide (PA) (red), and polyethylene terephthalate (PET) (green) via $\mathrm{pH}$ titration in $0.001 \mathrm{M} \mathrm{KCl}$. Values indicate means \pm standard error of the mean.

\subsection{Structural Diversity of the Early-Stage Biofilm}

We found differences in the numbers of structural diversities depending on the polymer type and incubation medium. After incubating the polymers in freshwater, we found the highest structural diversity on PA followed by a medium structural diversity on surfaces of PET and a low structural diversity on PVC. However, in seawater, PVC showed the highest structural diversity followed by a high structural diversity of PA and a medium structural diversity of PET (see Table 3).

We did not find any structures resembling microorganismal or non-microoroganismal origin forming a biofilm on any control image of the non-incubated polymers (see Figure S2). In botch incubation media, freshwater and seawater, microorganisms, and non-microoroganismal structures were abundant (see Figures S3 and S4).

\subsection{Morphological Strcutures Within Late-Stage Biofilms}

For comparison with the early stage biofilms we first investigated PA pellets incubated in freshwater and seawater for approximately two years for a clear idea of the structures forming a mature biofilm. The mature biofilm on PA pellets incubated in freshwater (Figure 2) showed a relatively smooth surface consisting of filamentous (f), compartmented multicellular (compf, mc), and smooth tubular (tub) structures with embedded elongated diatoms (edia). Figure 3 shows a mature biofilm on a PA pellet incubated in seawater, with microorganismal structures and marine diatoms (media) embedded in reticulate structures with a relatively rough surface. The overall structural diversity on the PA pellets after two years was higher in freshwater compared to the structural diversity observed in seawater (eight and four morphological structures, respectively). 

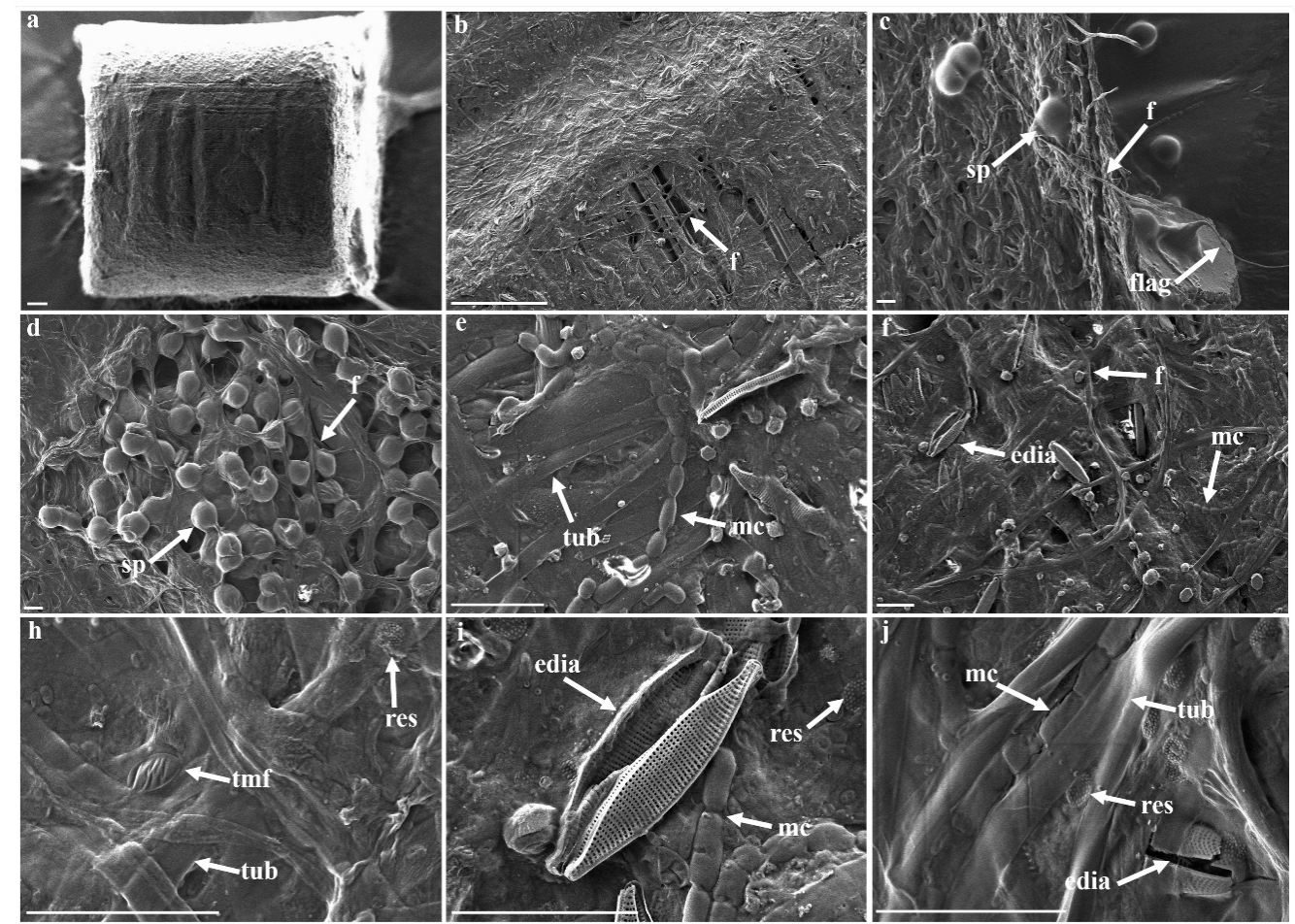

Figure 2. Scanning electron microscopy images of PA pellet incubated in freshwater for two years. Filamentous structures (f) almost completely cover the PA pellet $(\mathbf{a}, \mathbf{b})$. ( $\mathbf{c}-\mathbf{j})$ show higher magnifications of smooth late-stage biofilm. Sporous (sp), multicellular (mc), and tubular (tub) structures form the coalesced reticular structure of the biofilm. Elongated diatoms (edia) as exceptional rough elliptical structures (res) are on top and embedded within the biofilm. Furthermore, exceptional thin mucus-film-like (tmf) and flagella-like structures (flag) are highlighted. Scale bars: (a,b) $100 \mu \mathrm{m}$, (c-j) $10 \mu \mathrm{m}$.

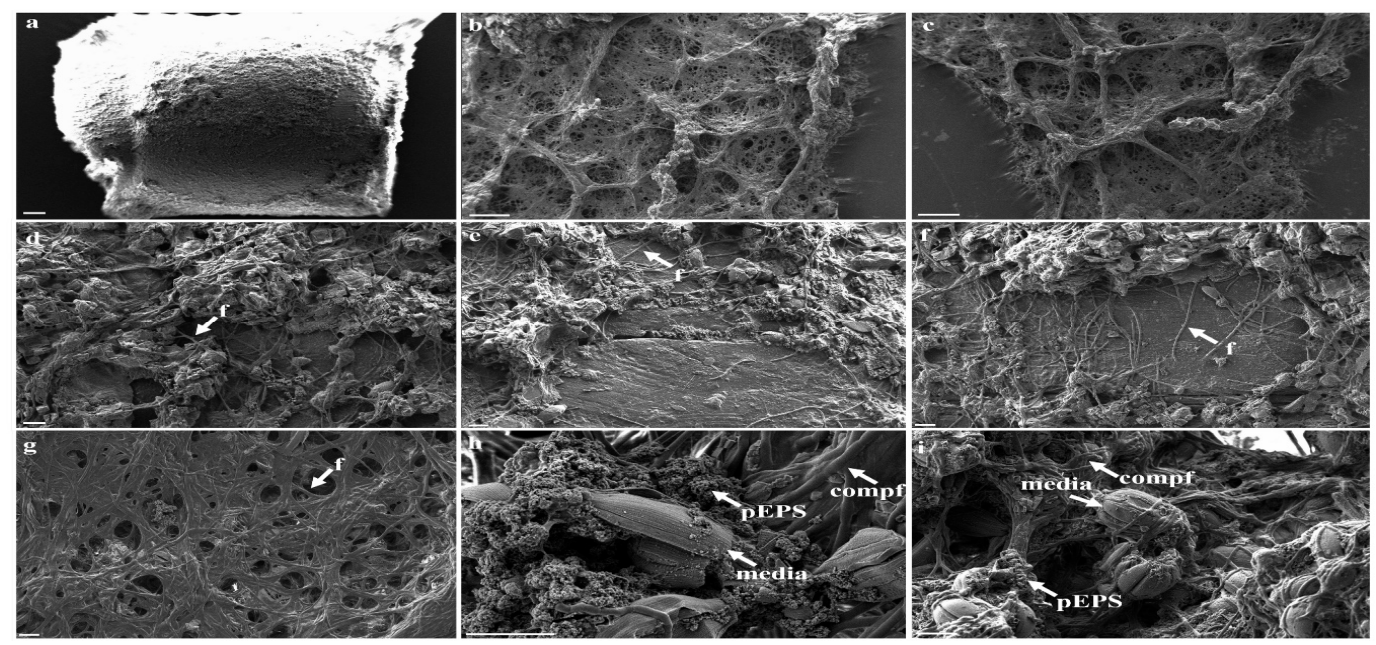

Figure 3. Scanning electron microscopy images of PA pellet incubated in seawater for two years. $(\mathbf{a}-\mathbf{j})$ Reticulate structures forming a mature biofilm consisting of $(\mathbf{e}-\mathbf{g})$ filamentous structures (f) and marine elongated diatoms (media). pEPS indicate particulate EPS. Higher magnification reveals filamentous cells being compartmented filaments (compf) resembling filamentous unbranched algae or cable bacteria. Scale bars: (a-c) $100 \mu \mathrm{m},(\mathbf{d}-\mathbf{i}) 10 \mu \mathrm{m}$. 


\subsection{Morphological Strcutures Within Early-Stage Biofilms}

All polymers incubated in seawater showed increasing amounts of salt crystals with increasing incubation time, which we could not detect for the polymers incubated in freshwater. Nevertheless, there were no obvious differences in the roughness or overall appearance for all polymer types from both incubation media for incubation times less than eleven days. However, we observed marked differences in structural diversity of early-stage biofilms for all polymer types, time points, and incubation media (Figures 4-9).

Although elongated diatoms (edia, bilateral, mostly sessile [57]) occurred in both late-stage biofilms from fresh- and seawater, diatoms $(d)$ were only observed once in the early-stage biofilms of PA after two weeks of incubation in freshwater (Figure 4). Interestingly, centric diatoms ( $c d$, radial, mostly planktonic [57]) exclusively occurred in early-stage biofilms originating from seawater and were found on all polymer type surfaces but not in late-stage biofilms on PA pellets.

Small coccoid and platelet-shaped structures ( $c c$, see e.g., Figure 6 after seven days of incubation) occurred in both incubation media on all polymer types. Whereas the round platelet $(r p)$ structures, which were also present in the pure incubation media (see Figure S3 and S4), were exclusively found on PA and PET in early-stage freshwater biofilms (see e.g., Figure 4 after two days of incubation and Figure 6 after seven days of incubation) but not on PVC at any time. Another interesting finding was that rod- and vibrio-shaped bacteria (rod, see e.g., Figure 7 after one day of incubation) were found on all polymer types incubated in both media, except for PVC incubated in freshwater (which was mainly covered by platelet-shaped $(p)$ and coccoid $(c c)$ structures). Albeit, the rod- and vibrio-shaped bacteria, which seemed to have a long flagellum (rodf, see e.g., Figure 5 after eleven days of incubation), only occurred on the surfaces of PA microplastic fragments independent of the incubation medium. Filamentous $(f)$ structures on PVC microplastic fragments incubated in freshwater after two weeks could possibly resemble flagella (see e.g., Figure 8 after 14 days of incubation), or also other bacterial appendices. In addition to the unicellular $(u c)$ structures (see e.g., Figure 7 after eleven days of incubation) observed on all polymer types incubated in seawater, the multicellular $(m c)$ structures were only observed on surfaces of PA and PET microplastic particles incubated for eleven days in freshwater (Figures 4 and 6). A comparison of the found morphological structures of both late and early stage biofilms with descriptions of biofilms from the literature is given in the following Section 4 . 

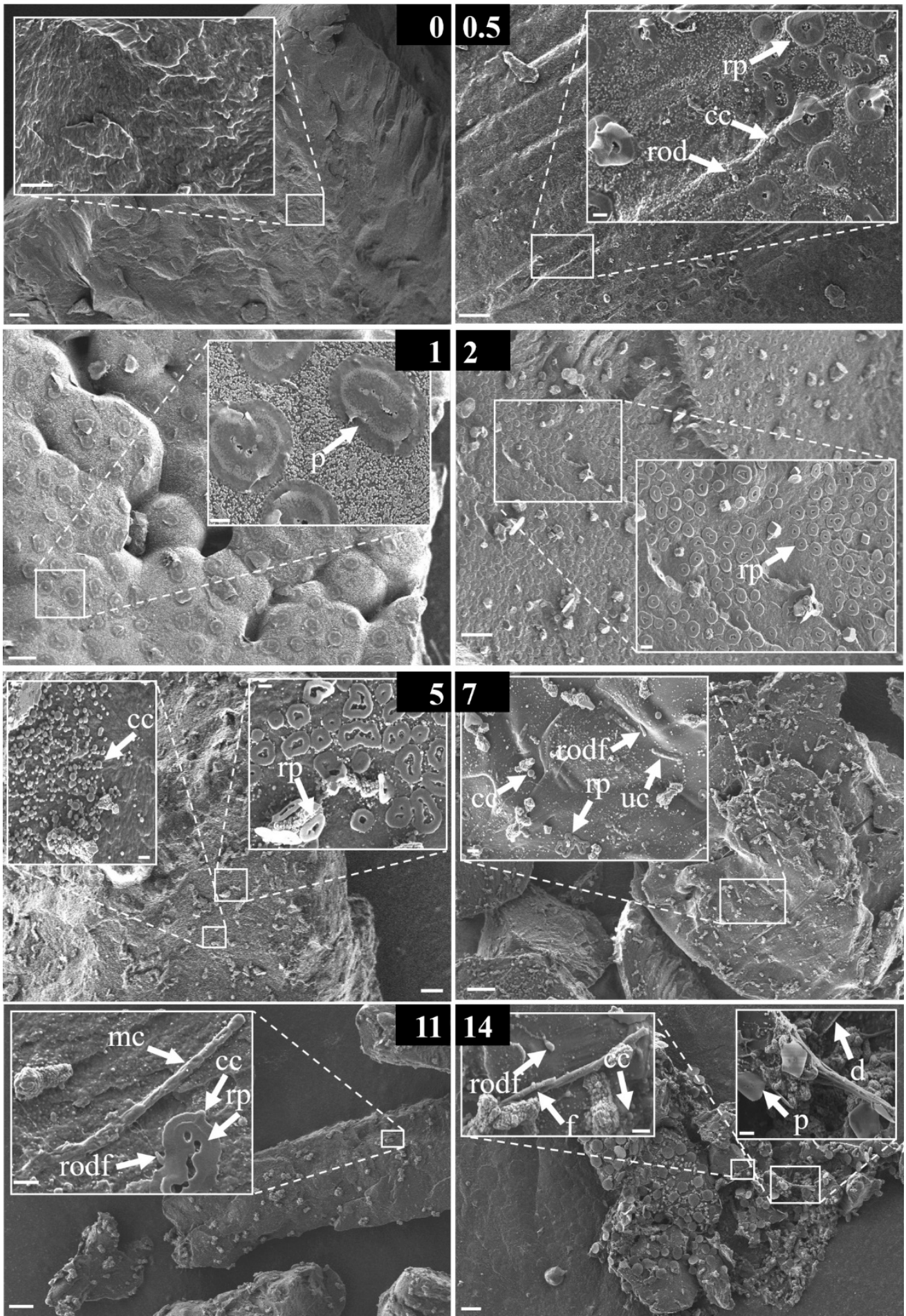

Figure 4. Scanning electron microscopy images of PA incubated in freshwater. Numbers in black boxes indicate incubation times in days $(0=$ raw material, $0.5=$ half day, $1=$ one day, $2=$ two days, $5=$ five days, 7 = seven days, $11=$ eleven days, $14=14$ days of incubation). Microorganismal structures are highlighted with arrows. $\mathrm{rod}=\mathrm{rod} /$ vibrio-shaped bacteria, $\mathrm{rodf}=\mathrm{rod} /$ vibrio-shaped bacteria with long flagella, $\mathrm{cc}=$ coccoid bacteria, $\mathrm{d}=$ diatom, $\mathrm{f}=$ filamentous structure, $\mathrm{mc}=$ multicellular structure, $\mathrm{rp}=$ round platelet structure, $\mathrm{p}=$ platelet structure, $\mathrm{uc}=$ unicellular structure. Scale bar: Large image $10 \mu \mathrm{m}$, magnified image $2 \mu \mathrm{m}$. 


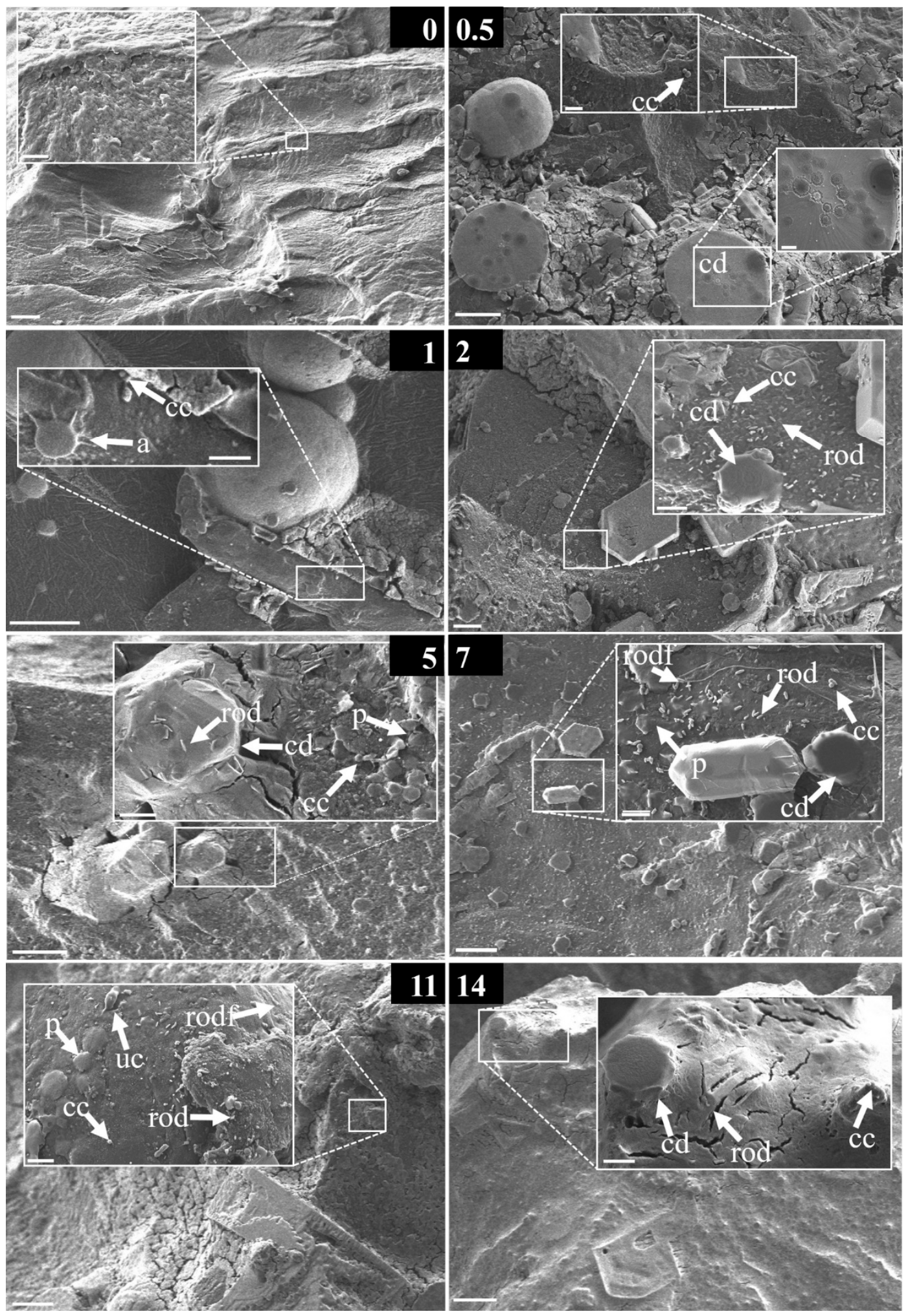

Figure 5. Scanning electron microscopy images of PA incubated in seawater. Numbers in black boxes indicate incubation times in days $(0=$ raw material, $0.5=$ half day, $1=$ one day, $2=$ two days, 5 = five days, 7 = seven days, $11=$ eleven days, $14=14$ days of incubation). Microorganismal structures are highlighted with arrows. $a=$ non-assignable structure, rod= rod-/vibrio-shaped bacteria, rodf $=$ rod-/vibrio-shaped bacteria with long flagella, $\mathrm{cc}=$ coccoid bacteria, $\mathrm{cd}=$ centric diatom, $\mathrm{p}=$ platelet structure, $\mathrm{uc}=$ unicellular structure. Scale bar: Large image $10 \mu \mathrm{m}$, magnified image $2 \mu \mathrm{m}$. 

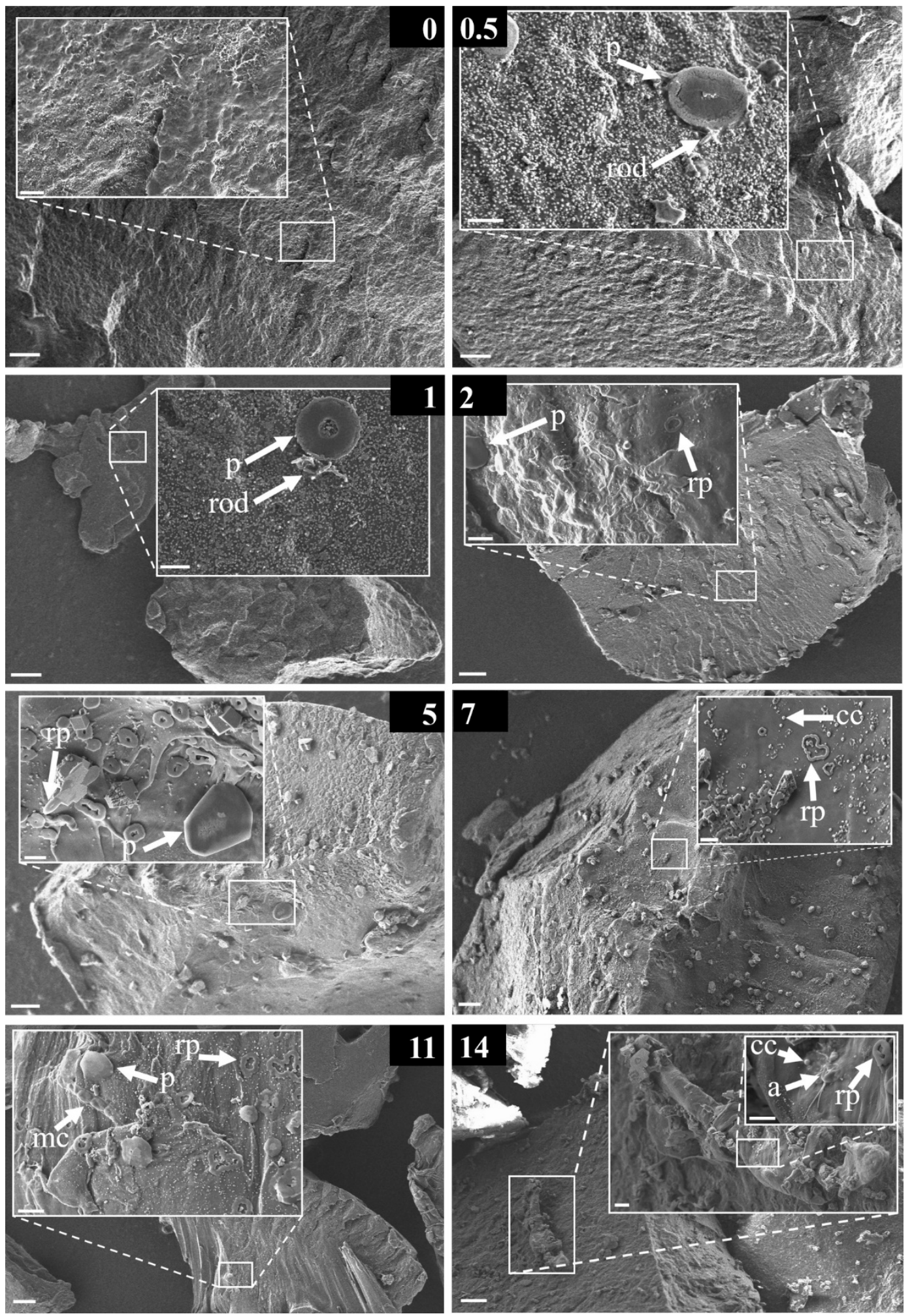

Figure 6. Scanning electron microscopy images of PET incubated in freshwater. Numbers in black boxes indicate incubation times in days $(0=$ raw material, $0.5=$ half day, $1=$ one day, $2=$ two days, $5=$ five days, 7 = seven days, 11 = eleven days, $14=14$ days of incubation). Microorganismal structures are highlighted with arrows. a = non-assignable structure, $\mathrm{rod}=\mathrm{rod} /$ vibrio-shaped bacteria, $\mathrm{cc}=\mathrm{coccoid}$ bacteria, $\mathrm{mc}=$ multicellular structure, $\mathrm{p}=$ platelet structure, $\mathrm{rp}=$ round platelet structure. Scale bar: Large image $10 \mu \mathrm{m}$, magnified image $2 \mu \mathrm{m}$. 


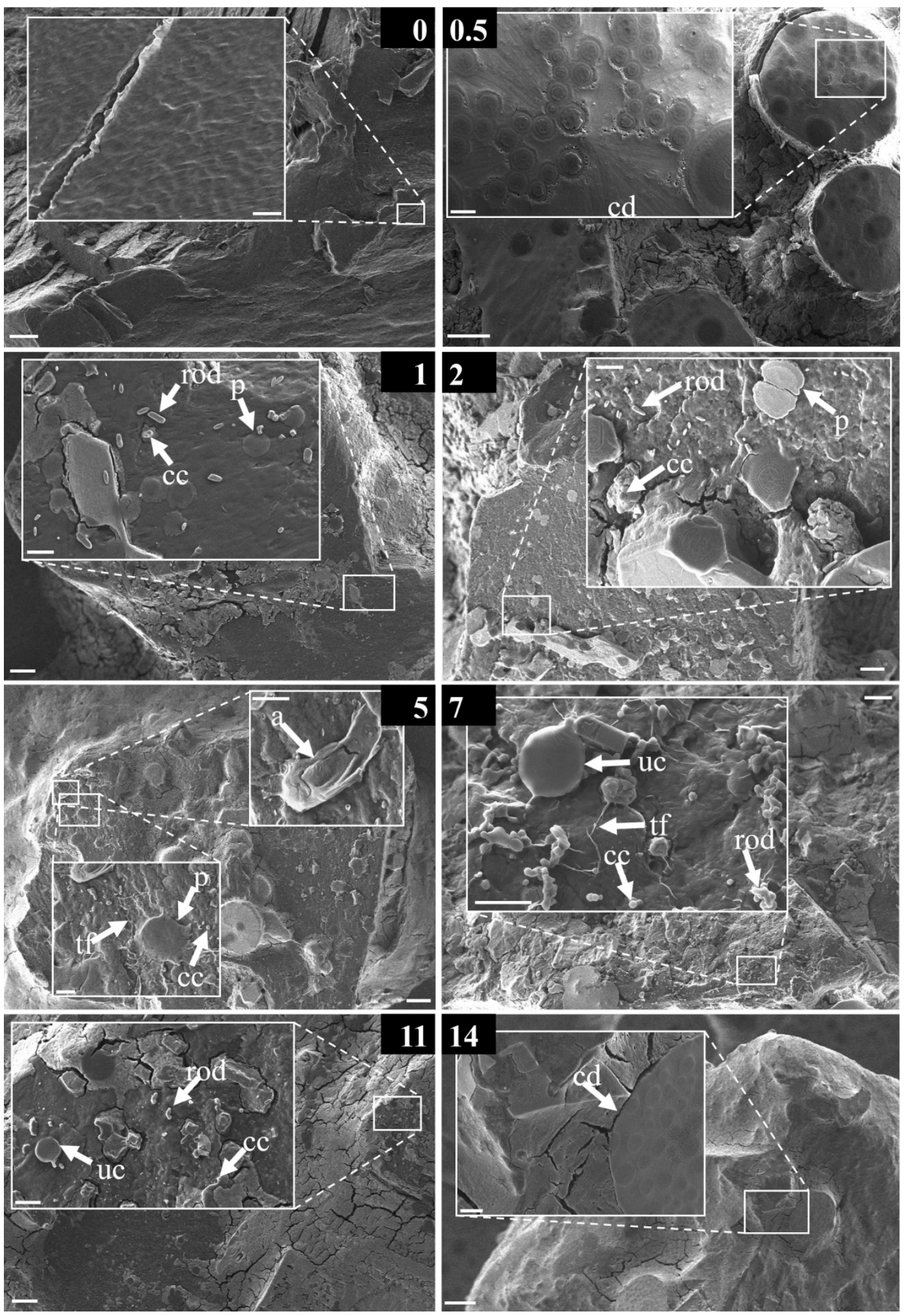

Figure 7. Scanning electron microscopy images of PET incubated in seawater. Numbers in black boxes indicate incubation times in days $(0=$ raw material, $0.5=$ half day, $1=$ one day, $2=$ two days, $5=$ five days, 7 = seven days, 11 = eleven days, $14=14$ days of incubation). Microorganismal structures are highlighted with arrows. $\mathrm{a}=$ non-assignable structure, $\mathrm{rod}=\mathrm{rod} /$ vibrio-shaped bacteria, $\mathrm{cc}=\mathrm{coccoid}$ bacteria, $\mathrm{p}=$ platelet structure, $\mathrm{tf}=$ thin film, $\mathrm{uc}=$ unicellular structure. Scale bar: Large image $10 \mu \mathrm{m}$, magnified image $2 \mu \mathrm{m}$. 

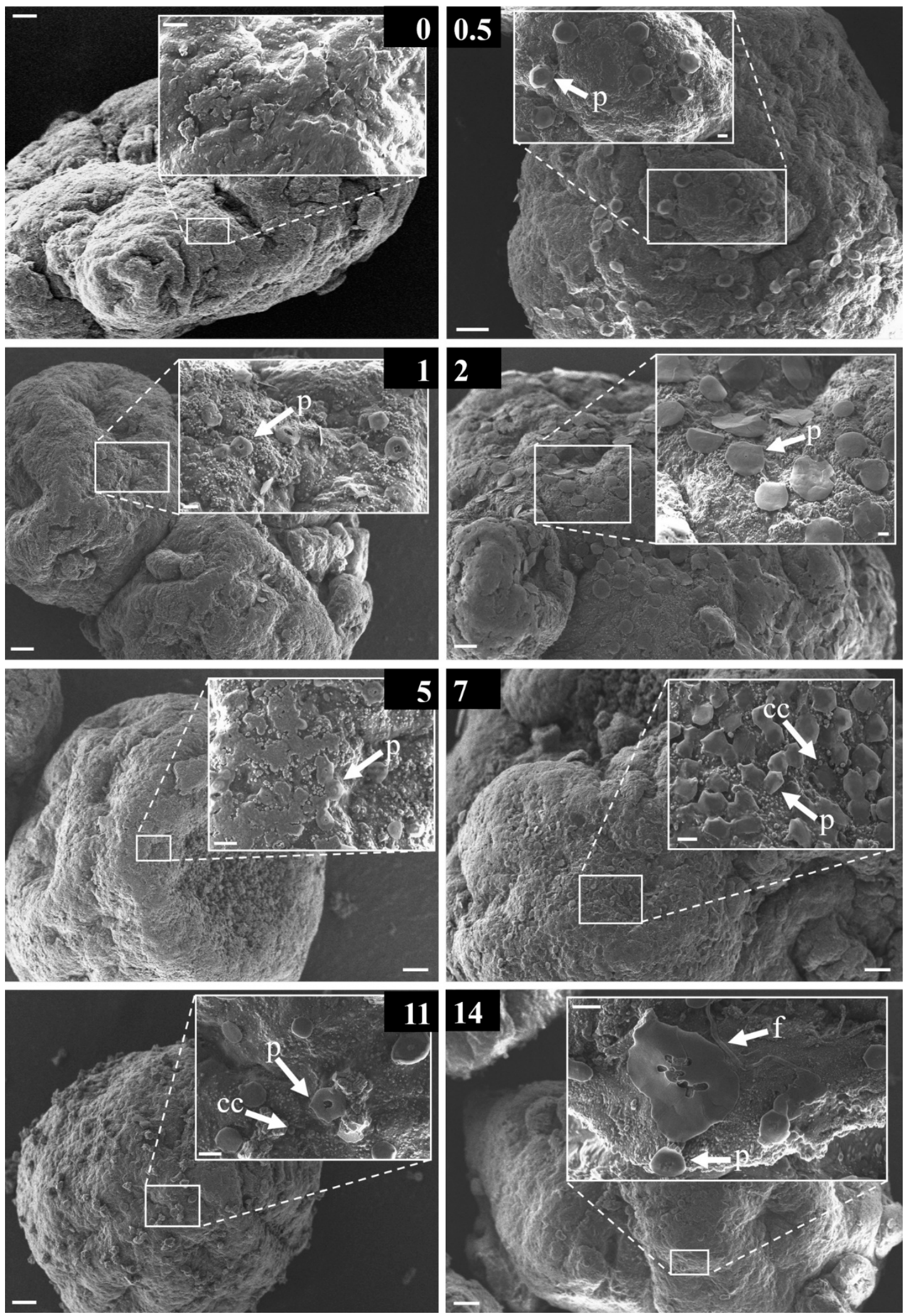

Figure 8. Scanning electron microscopy images of PVC incubated in freshwater. Numbers in black boxes indicate incubation times in days ( $0=$ raw material, $0.5=$ half day, $1=$ one day, $2=$ two days, 5 = five days, $7=$ seven days, $11=$ eleven days, $14=14$ days of incubation). Microorganismal structures are highlighted with arrows. $\mathrm{cc}=$ coccoid bacteria, $\mathrm{f}=$ filamentous structure, $\mathrm{p}=$ platelet structure. Scale bar: Large image $10 \mu \mathrm{m}$, magnified image $2 \mu \mathrm{m}$. 

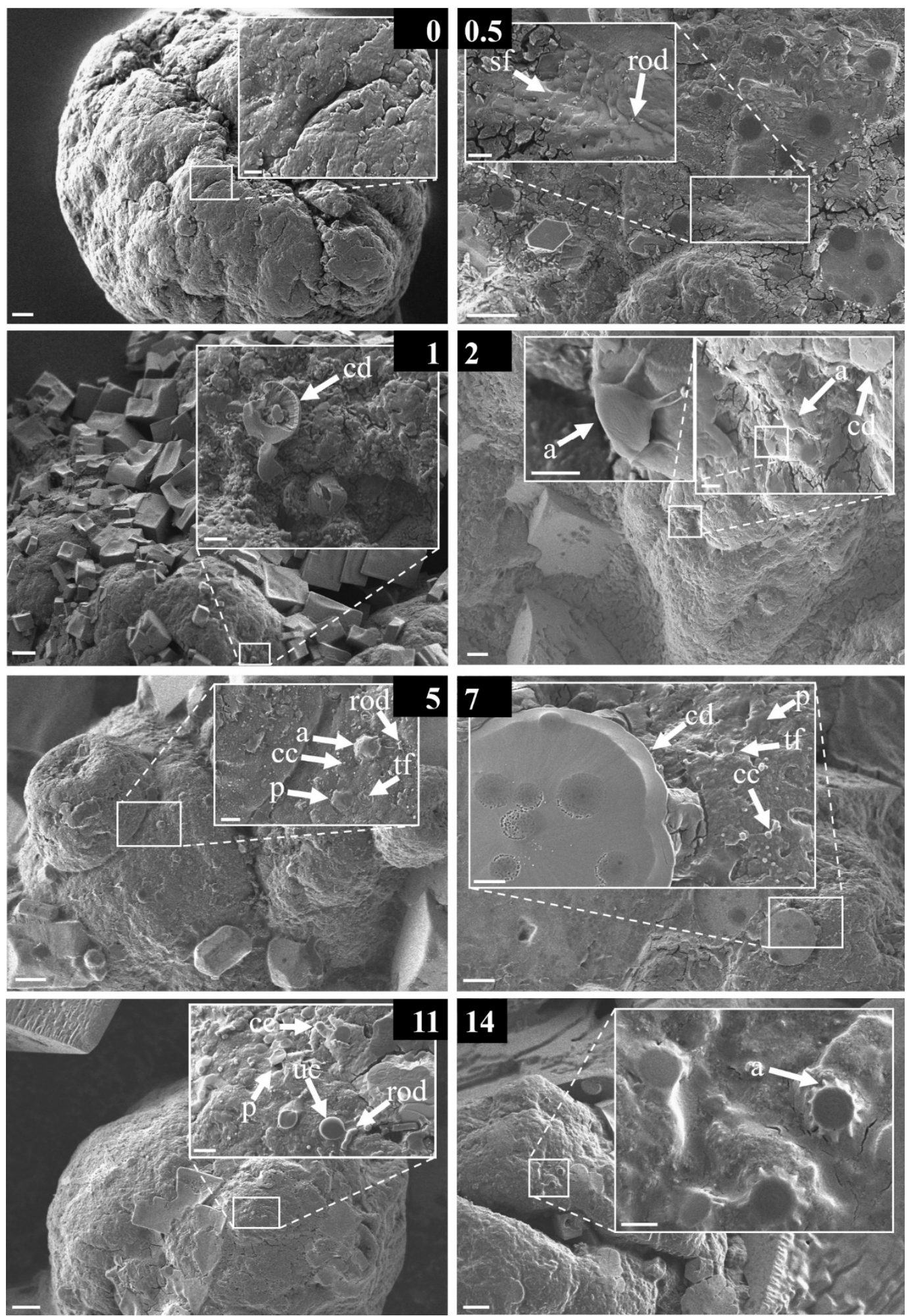

Figure 9. Scanning electron microscopy images of PVC incubated in seawater. Numbers in black boxes indicate incubation times in days $(0=$ raw material, $0.5=$ half day, $1=$ one day, $2=$ two days, $5=$ five days, 7 = seven days, $11=$ eleven days, $14=14$ days of incubation). Microorganismal structures are highlighted with arrows. $\mathrm{a}=$ non-assignable structure, $\mathrm{rod}=\mathrm{rod} / \mathrm{vibrio}-\mathrm{shaped}$ bacteria, $\mathrm{cc}=\mathrm{coccoid}$ bacteria, $\mathrm{cd}=$ centric diatom, $\mathrm{p}=$ platelet structure, $\mathrm{sf}=$ solid film, $\mathrm{tf}=$ thin film, $\mathrm{uc}=$ unicellular structure. Scale bar: Large image $10 \mu \mathrm{m}$, magnified image $2 \mu \mathrm{m}$. 


\section{Discussion}

\subsection{Correlation of Structural Diversity of Early-Stage Biofilms and Polymer Properties}

It has already been shown that several factors are influencing the results from $\zeta$-potential measurements, such as the $\mathrm{pH}$, particle concentration, and additionally the ionic strength of the measurement media [58]. The freshwater and artificial seawater medium used for incubation in our experiments both had a $\mathrm{pH}$ value of around 8. Interestingly, within this $\mathrm{pH}$ range, PA has the highest negative $\zeta$-potential followed by PET and PVC, showing the lowest negative $\zeta$-potential (see Table 3). It must be considered that beside the similar $\mathrm{pH}$ values of freshwater and seawater, the ionic strength may be different. Due to a higher amount of solved salts in seawater, the ionic strength is described to be 500 times higher than in freshwater [59]. As soon as the polymers face either freshwater or seawater, their surfaces may interact with available ions, influencing their $\zeta$-potential immediately. Therefore, we conducted a time-series incubation to monitor the time-dependent development of an early-stage biofilm formation and if this correlates with the initial $\zeta$-potential of the polymers. We found a clear correlation between the higher negative initial $\zeta$-potential and the highest structural diversity observed for PA when incubating the polymers for two weeks in freshwater, indicating that a negative charge of the polymer surface facilitates or triggers the settlement of microorganisms in freshwater. The latter correlation holds not true for the polymers incubated in seawater, as we found the highest structural diversity on PVC with the lowest negative $\zeta$-potential, followed with a high structural diversity on PA and PET showing medium structural diversities (see Table 3). This indicates that other surface properties than $\zeta$-potential may also play a role in the early stage biofilm formation in seawater.

Sanni et al. [60] describe that the settlement of bacteria on the polymer surface is strongly correlated with the polymer's morphology. The morphologies of the pristine polymers (before the incubation) visualized with SEM differed only slightly. PA and PET fragments showed similar, relatively smooth surfaces with some cracks, whereas PVC particles were relatively spherical with a slightly rougher surface and deeper cracks (see Figure S2). In addition to the morphology and initial $\zeta$-potential of the particles, the settlement of bacteria on the polymer surface is also correlated with the polymer's hydrophobicity [60]. The hydrophobicity of polymers can be measured via determining the contact angle of a liquid drop in contact with a solid surface [61]. The larger the contact angle, the larger the hydrophobicity of the solid surface. It was found that the contact angles for PA, PET, and PVC are $70^{\circ}$, $81^{\circ}$, and $87^{\circ}$, respectively [56]. Contact angles smaller than $90^{\circ}$ are usually associated with hydrophilic surfaces. This indicates that all polymers used in our experiments have hydrophilic surfaces, with PA being the most and PVC the least hydrophilic polymer. Nevertheless, contact angles are usually measured by applying a water drop on the polymers' clean and flat surfaces, which makes it difficult to measure the contact angle for irregularly shaped microplastic particles [56], such as those we used in our experiments. Next to the different initial $\zeta$-potential, morphology, and hydrophobicity of the three polymers used, the nature of the polymer itself may play an additional role. For instance, it has already been described that PVC has a low binding affinity to Staphylococci, which may also be true for other microorganisms because of its chloride content and the high content of plasticizers [62]. Interestingly, the structural diversity on PVC surfaces incubated in seawater was the highest observed, which is probably due to the fact that microorganisms from seawater are better adapted to higher chloride concentrations than freshwater microorganisms. This is most probably related to the overall higher salinity of seawater compared to freshwater, with sodium chloride being amongst the most common salts in the marine environment [63].

\subsection{Descriptive Analysis of the Observed Morphological Structures Forming a Late-Stage Biofilm}

The smooth tubular structures ( $t u b$, see Figure $2 e$ ) observed on the PA pellet incubated in freshwater for 2 years strongly resembled fungal hyphae [41], with indications of spore formation ( $s p$, see Figure 2d). Structures (Figure 3e) observed on PA incubated in seawater resemble the microbial cells that Zettler et al. [31] found on marine plastic debris (see Zettler et al. [31], Figure 2d), although 
in our case, the cells seemed attached to, instead of pitting into, the PA surface. The differences between seawater and freshwater in the late-stage biofilm structures may relate to different types of EPS and the differences in salinity of the incubation media. Two types of EPS are typically described, which are defined as dissolved and particulate EPS ( $p E P S$, Figure 3 h) [42,43]. For instance, diatoms show different morphological forms of EPS, such as highly crystalline and rigid fibrils (rough) up to highly hydrated and mucilaginous capsules (smooth) $[43,44]$. We observed diatoms in both biofilms originating from freshwater and seawater, which may explain the structural differences in the late-stage biofilms. The observed rough surface of the biofilm originating from seawater may be a combination of a higher proportion of particulate EPS and the higher salinity of seawater, resulting in salt crystals' embedment during the sample drying.

\subsection{Descriptive Analysis of the Observed Morphological Structures Forming an Early-Stage Biofilm}

The abundant platelet-shaped structures ( $p$, e.g., Figure 4 ) observed already after one-day incubation on all polymer surfaces independent of the incubation medium were likely not of biological origin. While they remain unidentified and could indicate desorption or outcropping processes within polymers, some resembled triangular scales of the testate amoeba Penardeugenia [45] and scales of other protists of the genera Thaumatomastix and Reckertia [46]. However, the platelet-shaped structures may also originate from polygonal cells [53] or damaged Staphylococcus aureus-like cells [47], as we found small coccoid structures ( $c c$, see e.g., Figure 6 after seven days of incubation) in both incubation media and on all polymer types, just as the platelet-shaped structures. Bacterial cocci are typically $0.5-1.5 \mu \mathrm{m}$ in size [64], which is about the size range of the coccoid-shaped structures we observed. Interestingly, round platelet $(r p)$ structures were exclusively found on PA and PET in early-stage freshwater biofilms (see e.g., Figure 4 after two days of incubation and Figure 6 after seven days of incubation). We did not observe round platelet structures on PVC, but at any time in the pure freshwater incubation medium (SEM images of both incubation media, see Figure S3 and S4), we can exclude that these structures originate from drying effects or from the early degradation processes of the polymers. The round platelet structures also resembled scales from planktonic algae such as silica-scaled chrysophytes [48], but their early appearance and very regular distribution make them unlikely to be of microorganismal but rather inorganic origin or drying effects.

The multicellular structures found in the early-stage biofilms resemble those found in the late-stage freshwater biofilms, indicating that these organisms may attach to surfaces already after less than two weeks of incubation and further develop a mature biofilm. The multicellular structures could be of diverse origin but resemble filamentous microorganisms such as cable bacteria [49] or multicellular Cyanobacteria [50]. Abundantly found on the surfaces of polymers incubated in seawater were structures resembling centric diatoms $[12,44]$ (cd, see e.g., Figure 9 after one day of incubation). In their comprehensive review, Hoagland et al. [44] described different mechanisms for the attachment of elongated and centric diatoms on surfaces using EPS in the form of stalks, tubes, apical pads, adhering films, fibrils, or cell coatings. We observed some structures in the very early-stage of biofilm formation, which we named exceptional microorganismal structures (e.g., in Figure 5 after one day of incubation). These were exclusively found in seawater treatments and may be centric diatoms forming fibrils or stalks [44]. However, these structures with about $3 \mu \mathrm{m}$ in diameter are at the lower size range of small centric diatoms [51,52]. Furthermore, we found film-like structures on PET and PVC incubated in seawater that may be part of extruded EPS (Figures 7 and 9). On PET, we found exclusively thin and smooth films (tf, see e.g., Figure 7 after seven days of incubation), which were additionally accompanied by a solid film (sf, see e.g., Figure 9 after half a day of incubation) on PVC. When considering the five successive steps of biofilm formation described by Renner and Weibel [37], EPS's excretion initiates the second step of biofilm formation, which starts the formation of a mature biofilm. This means that for PET and PVC incubated in seawater, five days and one week of incubation, respectively, initiates the maturing of a biofilm. Furthermore, our observations demonstrate that the structural diversity on the surfaces of the three polymers from either freshwater or seawater differed, although 
the same experimental conditions were chosen for each polymer-environmental medium combination. This highlights that the properties of a polymer itself may play a crucial role for the formation of a very early-stage biofilm on different plastics.

\subsection{Potential Ecological Implications of Our Findings}

De Tender et al. [65] showed the temporal dynamics of bacterial and fungal colonization on plastic materials within almost one year in the marine environment. They found community changes by using genetic screening methods and additionally visualized the development of the late-stage biofilm. Within the observed time periods of one month, the maturing of a biofilm was macroscopically visible [65]. For plastics incubated in seawater, it has already been shown that biofilms enhance polymer palatability by mimicking an organic origin [26,27]. Exposure of polystyrene beads to filtered seawater for three weeks [26] and polyethylene for one month of incubation directly in the marine environment [27] increased the ingestion, possibly increasing the physical and chemical risks from plastic particles to the tested organisms. However, this phenomenon has not been shown for other polymer types incubated for shorter time periods or incubated in freshwater. Hence, our results indicate that even short-term environmental exposure may be sufficient that a variety of organisms from different ecosystems mistake microplastics with food.

\section{Conclusions}

Here, we show that already, half a day of incubation in either freshwater or seawater initiates the formation of an early-stage biofilm by the attachment of microbial structures, but possibly also the appearance of non-microbial structures. The overall structural diversity of biofilm structures increased within two weeks for all polymer types in both incubation media. We show that a mature biofilm on PA differs in its composition depending on the incubation medium and found that the early-stage biofilm formation on three different polymers depends on the incubation medium and is most probably related to the polymers' surface properties. In freshwater, we found a correlation of the initial $\zeta$-potential of the particles with the structural diversity on the polymer's surfaces. PA, with the highest negative initial $\zeta$-potential, showed the highest structural diversity and PVC with the lowest negative initial $\zeta$-potential showed the lowest structural diversity. However, in seawater, PVC showed the highest structural diversity with the lowest negative initial $\zeta$-potential. For seawater, we did not find a clear correlation with the initial $\zeta$-potential, as there were not such apparent differences between PET and PA. Furthermore, we show that the early-stage biofilm formation on polymers seems additionally being dependent on the polymers' surface morphology and the polymers' chemical composition. Our findings emphasize the complexity that can be related to research on microplastic biofilms and show that not solely the polymer type but also the incubation medium, time, and the initial surface properties of the used polymers may play an important role for the initial colonization of plastic surfaces.

Supplementary Materials: The following figures are available online at http://www.mdpi.com/2073-4441/12/11/ 3216/s1, Figure S1: Photographs of the sampling sites for the incubation media, Figure S2: Scanning electron microscopy images of the three polymer raw materials. Figure S3: Scanning electron microscopy images of the freshwater incubation medium after evaporation of water, Figure S4: Scanning electron microscopy images of the saltwater incubation medium after evaporation of water.

Author Contributions: A.F.R.M.R., A.C.S. and C.L. designed the experiments and A.F.R.M.R., A.C.S., A.C., A.F., T.L., M.G.J.L., H.K. and C.L. wrote the manuscript. A.F.R.M.R. and A.C.S. conducted the experiments and prepared samples for SEM, A.F.R.M.R., A.C.S., C.L., M.G.J.L., H.K. and T.L. evaluated the structural diversity A.C. conducted the $\zeta$-potential measurements, A.C. and A.F. evaluated the $\zeta$-potential data; All authors have read and agreed to the published version of the manuscript.

Funding: This work was supported by the Deutsche Forschungsgemeinschaft (DFG, German Research Foundation)—project number 391977956 - SFB 1357. A.F.R.M.R. was supported by a scholarship of the Elite Network of Bavaria (BayEFG) and by the University of Bayreuth Graduate School. 
Acknowledgments: We thank Lothar Benker (Macromolecular Chemistry II) for milling and providing the three polymers used, Martina Heider (Bayreuth Institute of Macromolecular Research) for assistance with SEM and all technicians from the Department of Animal Ecology I and the Biological Physics Group for their support with the experiments. We thank the keylab electrokinetics at the ipfdd and especially Alla Synytska for the support with the data analyses. We also thank our colleagues for the helpful discussions with the manuscript.

Conflicts of Interest: The authors declare no conflict of interest.

\section{References}

1. Andrady, A.L.; Neal, M.A. Applications and societal benefits of plastics. Philos. Trans. R. Soc. B Biol. Sci. 2009, 364, 1977-1984. [CrossRef]

2. Barnes, D.K.A.; Galgani, F.; Thompson, R.C.; Barlaz, M. Accumulation and fragmentation of plastic debris in global environments. Philos. Trans. R. Soc. Lond. B Biol. Sci. 2009, 364, 1985-1998. [CrossRef]

3. Thompson, R.C.; Olsen, Y.; Mitchell, R.P.; Davis, A.; Rowland, S.J.; John, A.W.J.; McGonigle, D.; Russell, A.E. Lost at sea: Where is all the plastic. Science 2004, 304, 838. [CrossRef]

4. Arthur, C.; Baker, J.; Bamford, H. Proceedings of the International Research Workshop on the Occurrence, Effects, and Fate of Microplastic Marine Debris. In Conference Proceedings; Environmental Science: Silver Spring, MD, USA, 2008; p. 530.

5. Andrady, A.L. The plastic in microplastics: A review. Mar. Pollut. Bull. 2017, 119, 12-22. [CrossRef]

6. Dris, R.; Imhof, H.; Sanchez, W.; Gasperi, J.; Galgani, F.; Tassin, B.; Laforsch, C. Beyond the ocean: Contamination of freshwater ecosystems with (micro-) plastic particles. Environ. Chem. 2015. [CrossRef]

7. Piehl, S.; Leibner, A.; Löder, M.G.J.; Dris, R.; Bogner, C.; Laforsch, C. Identification and quantification of macro- and microplastics on an agricultural farmland. Sci. Rep. 2018, 8, 17950. [CrossRef] [PubMed]

8. Dris, R.; Gasperi, J.; Saad, M.; Mirande, C.; Tassin, B. Synthetic fibers in atmospheric fallout: A source of microplastics in the environment? Mar. Pollut. Bull. 2016, 104, 290-293. [CrossRef] [PubMed]

9. Gasperi, J.; Wright, S.L.; Dris, R.; Collard, F.; Mandin, C.; Guerrouache, M.; Langlois, V.; Kelly, F.J.; Tassin, B. Microplastics in air: Are we breathing it in? Curr. Opin. Environ. Sci. Health 2018, 1, 1-5. [CrossRef]

10. Imhof, H.K.; Ivleva, N.P.; Schmid, J.; Niessner, R.; Laforsch, C. Contamination of beach sediments of a subalpine lake with microplastic particles. Curr. Biol. 2013, 23, R867-R868. [CrossRef]

11. Imhof, H.K.; Sigl, R.; Brauer, E.; Feyl, S.; Giesemann, P.; Klink, S.; Leupolz, K.; Löder, M.G.J.; Löschel, L.A.; Missun, J.; et al. Spatial and temporal variation of macro-, meso- and microplastic abundance on a remote coral island of the Maldives, Indian Ocean. Mar. Pollut. Bull. 2017, 116, 340-347. [CrossRef]

12. Lacerda, A.L.d.F.; Rodrigues, L. dos S.; van Sebille, E.; Rodrigues, F.L.; Ribeiro, L.; Secchi, E.R.; Kessler, F.; Proietti, M.C. Plastics in sea surface waters around the Antarctic Peninsula. Sci. Rep. 2019, 9, 3977. [CrossRef] [PubMed]

13. Woodall, L.C.; Sanchez-Vidal, A.; Canals, M.; Paterson, G.L.J.; Coppock, R.; Sleight, V.; Calafat, A.; Rogers, A.D.; Narayanaswamy, B.E.; Thompson, R.C. The deep sea is a major sink for microplastic debris. R. Soc. Open Sci. 2014, 1. [CrossRef]

14. Laist, D. Impacts of marine debris: Entanglement of marine life in marine debris including a comprehensive list of species with entanglement and ingestion records. In Marine Debris—Sources, Impacts Solutions; Coe, J.M., Rogers, D.B., Eds.; Springer: New York, NY, USA, 1997; pp. 99-139. [CrossRef]

15. Harper, P.C.; Fowler, J.A. Plastic pellets in New Zealand storm-killed prions (Pachyptila spp.) 1958-1977. Notornis 1987, 34, 65-70.

16. Cole, M.; Lindeque, P.; Fileman, E.; Halsband, C.; Goodhead, R.; Moger, J.; Galloway, T.S. Microplastic ingestion by zooplankton. Environ. Sci. Technol. 2013, 47, 6646-6655. [CrossRef] [PubMed]

17. Browne, M.A.; Dissanayake, A.; Galloway, T.S.; Lowe, D.M.; Thompson, R.C. Ingested microscopic plastic translocates to the circulatory system of the mussel, Mytilus edulis (L.). Environ. Sci. Technol. 2008, 42, 5026-5031. [CrossRef]

18. von Moos, N.; Burkhardt-Holm, P.; Koehler, A. Uptake and E ff ects of Microplastics on Cells and Tissue of the Blue Mussel Mytilus edulis L. after an Experimental Exposure. Environ. Sci. Technol. 2012, 46, 327-335. [CrossRef]

19. Lu, Y.; Zhang, Y.; Deng, Y.; Jiang, W.; Zhao, Y.; Geng, J.; Ding, L.; Ren, H. Uptake and Accumulation of Polystyrene Microplastics in Zebrafish (Danio rerio) and Toxic Effects in Liver. Environ. Sci. Technol. 2016, 50, 4054-4060. [CrossRef] 
20. Rummel, C.D.; Löder, M.G.J.; Fricke, N.F.; Lang, T.; Griebeler, E.; Janke, M.; Gerdts, G. Plastic ingestion by pelagic and demersal fish from the North Sea and Baltic Sea. Mar. Pollut. Bull. 2015. [CrossRef]

21. Prata, J.C.; da Costa, J.P.; Lopes, I.; Duarte, A.C.; Rocha-Santos, T. Environmental exposure to microplastics: An overview on possible human health effects. Sci. Total Environ. 2020, 702, 134455. [CrossRef]

22. Welden, N.A.; Lusher, A.L. Microplastics: From Origin to Impacts; Elsevier Inc.: New York, NY, USA, 2020; Volume 32, ISBN 9780128178805. [CrossRef]

23. Ryan, P.G. Effects of ingested plastic on seabird feeding: Evidence from chickens. Mar. Pollut. Bull. 1988, 19, 125-128. [CrossRef]

24. Koelmans, A.A.; Bakir, A.; Burton, G.A.; Janssen, C.R. Microplastic as a Vector for Chemicals in the Aquatic Environment: Critical Review and Model-Supported Reinterpretation of Empirical Studies. Environ. Sci. Technol. 2016, 50, 3315-3326. [CrossRef] [PubMed]

25. Kirstein, I.V.; Kirmizi, S.; Wichels, A.; Garin-Fernandez, A.; Erler, R.; Löder, M.; Gerdts, G. Dangerous hitchhikers? Evidence for potentially pathogenic Vibrio spp. on microplastic particles. Mar. Environ. Res. 2016, 120, 1-8. [CrossRef] [PubMed]

26. Vroom, R.J.E.; Koelmans, A.A.; Besseling, E.; Halsband, C. Aging of microplastics promotes their ingestion by marine zooplankton. Environ. Pollut. 2017, 231, 987-996. [CrossRef] [PubMed]

27. Hodgson, D.J.; Bréchon, A.L.; Thompson, R.C. Ingestion and fragmentation of plastic carrier bags by the amphipod Orchestia gammarellus: Effects of plastic type and fouling load. Mar. Pollut. Bull. 2018, 127, 154-159. [CrossRef] [PubMed]

28. Liu, P.; Zhan, X.; Wu, X.; Li, J.; Wang, H.; Gao, S. Effect of weathering on environmental behavior of microplastics: Properties, sorption and potential risks. Chemosphere 2020, 242. [CrossRef]

29. Lobelle, D.; Cunliffe, M. Early microbial biofilm formation on marine plastic debris. Mar. Pollut. Bull. 2011, 62, 197-200. [CrossRef]

30. Oberbeckmann, S.; Loeder, M.G.J.; Gerdts, G.; Osborn, A.M. Spatial and seasonal variation in diversity and structure of microbial biofilms on marine plastics in Northern European waters. FEMS Microbiol. Ecol. 2014, 2, 478-492. [CrossRef]

31. Zettler, E.R.; Mincer, T.J.; Amaral-zettler, L.A. Life in the 'Plastisphere ': Microbial communities on plastic marine debris. Environ. Sci. Technol. 2013, 47, 7137-7146. [CrossRef]

32. Dang, H.; Li, T.; Chen, M.; Huang, G. Cross-ocean distribution of Rhodobacterales bacteria as primary surface colonizers in temperate coastal marine waters. Appl. Environ. Microbiol. 2008, 74, 52-60. [CrossRef]

33. Webb, H.K.; Crawford, R.J.; Sawabe, T.; Ivanova, E.P. Poly(ethylene terephthalate) polymer surfaces as a substrate for bacterial attachment and biofilm formation. Microbes Environ. 2009, 24, 39-42. [CrossRef]

34. Hossain, M.R.; Jiang, M.; Wei, Q.H.; Leff, L.G. Microplastic surface properties affect bacterial colonization in freshwater. J. Basic Microbiol. 2019, 59, 54-61. [CrossRef] [PubMed]

35. Artham, T.; Sudhakar, M.; Venkatesan, R.; Madhavan Nair, C.; Murty, K.V.G.K.; Doble, M. Biofouling and stability of synthetic polymers in sea water. Int. Biodeterior. Biodegrad. 2009, 63, 884-890. [CrossRef]

36. Loeb, G.; Neihof, R. Marine conditioning films. Adv. Chem. 1975, 145, 319-335. [CrossRef]

37. Renner, L.D.; Weibel, D.B. Physicochemical regulation of biofilm formation. MRS Bull. 2011, 36, 347-355. [CrossRef] [PubMed]

38. Sutherland, I.W. The biofilm matrix-An immobilized but dynamic microbial environment. Trends Microbiol. 2001, 9, 222-227. [CrossRef] [PubMed]

39. Rummel, C.D.; Jahnke, A.; Gorokhova, E.; Kühnel, D.; Schmitt-Jansen, M. The Impacts of Biofilm Formation on the Fate and Potential Effects of Microplastic in the Aquatic Environment. Environ. Sci. Technol. Lett. 2017. [CrossRef]

40. PlasticsEurope (Association of Plastic Manufacturers). Conversio Market E Strategy GmbH Plastics-The Facts 2019; PlasticsEurope (Association of Plastic Manufacturers): Brussels, Belgium, 2019.

41. González-Ramírez, A.I.; Ramírez-Granillo, A.; Medina-Canales, M.G.; Rodríguez-Tovar, A.V.; Martínez-Rivera, M.A. Analysis and description of the stages of Aspergillus fumigatus biofilm formation using scanning electron microscopy. BMC Microbiol. 2016, 16, 243. [CrossRef]

42. Solmaz, K.; Ozcan, Y.; Mercan Dogan, N.; Bozkaya, O.; Ide, S. Characterization and Production of Extracellular Polysaccharides (EPS) by Bacillus Pseudomycoides U10. Environments 2018, 5, 63. [CrossRef] 
43. Zhang, S.; Xu, C.; Santschi, P.H. Chemical composition and 234Th (IV) binding of extracellular polymeric substances (EPS) produced by the marine diatom Amphora sp. Mar. Chem. 2008, 112, 81-92. [CrossRef]

44. Hoagland, K.D.; Rosowski, J.R.; Gretz, M.R.; Roemer, S.C. Diatom extracellular polymeric substances: Function, fine structure, chemistry, and physiology. J. Phycol. 1993, 29, 537-566. [CrossRef]

45. Dumack, K.; Siemensma, F.; Bonkowski, M. Rediscovery of the Testate Amoeba Genus Penardeugenia (Thaumatomonadida, Imbricatea). Protist 2018, 169, 29-42. [CrossRef] [PubMed]

46. Nicholls, K.H. New and little-known marine and freshwater species of the silica-scaled genera Thaumatomastix and Reckertia (Cercozoa: Thaumatomonadida). J. Mar. Biol. Assoc. UK 2013, 93, 1231-1244. [CrossRef]

47. Saraeva, I.; Kudryashov, S.I.; Danilov, P.; Busleev, N.; Tolordava, E.R.; Rudenko, A.A.; Zayarny, D.; Ionin, A.; Romanova, Y.M. Polarization-Sensitive Surface-Enhanced In Situ Photoluminescence Spectroscopy of S. aureus Bacteria on Gold Nanospikes. Sensors 2020, 20, 2466. [CrossRef]

48. Bessudova, A.Y.; Domysheva, V.M.; Firsova, A.D.; Likhoshway, Y.V. Silica-scaled chrysophytes of Lake Baikal. Acta Biol. Sib. 2017, 3, 47. [CrossRef]

49. Reimers, C.E.; Li, C.; Graw, M.F.; Schrader, P.S.; Wolf, M. The identification of cable bacteria attached to the anode of a benthic microbial fuel cell: Evidence of long distance extracellular electron transport to electrodes. Front. Microbiol. 2017, 8, 2055. [CrossRef]

50. Koon, M.A.; Almohammed Ali, K.; Speaker, R.M.; McGrath, J.P.; Linton, E.W.; Steinhilb, M.L. Preparation of prokaryotic and eukaryotic organisms using chemical drying for morphological analysis in scanning electron microscopy (SEM). J. Vis. Exp. 2019, 2019, 1-10. [CrossRef]

51. Margalef, R. Size of centric diatoms as an ecological indicator. SIL Commun. 1953-1996 1969, 17, $202-210$. [CrossRef]

52. Wu, Y.; Li, Z.; Du, W.; Gao, K. Physiological response of marine centric diatoms to ultraviolet radiation, with special reference to cell size. J. Photochem. Photobiol. B Biol. 2015, 153, 1-6. [CrossRef]

53. Oliver, P.G.; Rodrigues, C.F. Thyasiridae (mollusca: Bivalvia) from the Kemp caldera hydrothermal site, south sandwich islands, Antarctica. J. Conchol. 2017, 42, 267-282. [CrossRef]

54. Lowry, G.V.; Hill, R.J.; Harper, S.; Rawle, A.F.; Hendren, C.O.; Klaessig, F.; Nobbmann, U.; Sayre, P.; Rumble, J. Guidance to improve the scientific value of zeta-potential measurements in nanoEHS. Environ. Sci. Nano 2016, 3, 953-965. [CrossRef]

55. Drechsler, A.; Caspari, A.; Synytska, A. Influence of roughness and capillary size on the zeta potential values obtained by streaming potential measurements. Surf. Interface Anal. 2020, 1-5. [CrossRef]

56. Heinrich, P.; Hanslik, L.; Kämmer, N.; Braunbeck, T. The tox is in the detail: Technical fundamentals for designing, performing, and interpreting experiments on toxicity of microplastics and associated substances. Environ. Sci. Pollut. Res. 2020, 27, 22292-22318. [CrossRef]

57. Chiovitti, A.; Dugdale, T.M.; Wetherbee, R. Diatom Adhesives: Molecular and Mechanical Properties. Biol. Adhes. 2006, 1, 79-103. [CrossRef]

58. Bhattacharjee, S. DLS and zeta potential-What they are and what they are not? J. Control. Release 2016, 235, 337-351. [CrossRef]

59. Chepkwony, N.K.; Berne, C.; Brun, Y.V. Comparative analysis of ionic strength tolerance between freshwater and marine Caulobacterales adhesins. J. Bacteriol. 2019, 201, 18. [CrossRef]

60. Sanni, O.; Chang, C.Y.; Anderson, D.G.; Langer, R.; Davies, M.C.; Williams, P.M.; Williams, P.; Alexander, M.R.; Hook, A.L. Bacterial attachment to polymeric materials correlates with molecular flexibility and hydrophilicity. Adv. Healthc. Mater. 2015, 4, 695-701. [CrossRef]

61. Dwivedi, C.; Pandey, I.; Himanshu, P.; Ramteke, P.W.; Pandey, A.C.; Mishra, S.B.; Patil, S. Electrospun Nanofibrous Scaffold as a Potential Carrier of Antimicrobial Therapeutics for Diabetic Wound Healing and Tissue Regeneration; Elsevier Inc.: New York, NY, USA, 2017; ISBN 9780323527279. [CrossRef]

62. Frank, E.; Merete, W.; Lotte, C.; Anne-lise, H.; Vibke, T.R.; Clemmensen, I. Attachment of staphylococci to different plastic tubes in vitro. Med. Microbiol. 1994, 40, 37-42. [CrossRef]

63. Gorrell, H.A. Classification of Formation Waters Based on Sodium Chloride Content: GEOLOGICAL NOTES. Am. Assoc. Pet. Geol. Bull. 1958, 42, 2522. [CrossRef] 
64. Harris, L.G.; Foster, S.J.; Richards, R.G.; Lambert, P.; Stickler, D.; Eley, A. An introduction to Staphylococcus aureus, and techniques for identifyingand quantifying $S$. aureus adhesins in relation to adhesion to biomaterials:Review. Eur. Cells Mater. 2002, 4, 39-60. [CrossRef]

65. De Tender, C.; Devriese, L.I.; Haegeman, A.; Maes, S.; Vangeyte, J.; Cattrijsse, A.; Dawyndt, P.; Ruttink, T. Temporal Dynamics of Bacterial and Fungal Colonization on Plastic Debris in the North Sea. Environ. Sci. Technol. 2017, 51, 7350-7360. [CrossRef]

Publisher's Note: MDPI stays neutral with regard to jurisdictional claims in published maps and institutional affiliations.

(C) 2020 by the authors. Licensee MDPI, Basel, Switzerland. This article is an open access article distributed under the terms and conditions of the Creative Commons Attribution (CC BY) license (http://creativecommons.org/licenses/by/4.0/). 